\title{
CHRONIC OBSTRUCTIVE PULMONARY DISEASE IN IRON-STEEL AND FERROCHROME INDUSTRY WORKERS
}

\author{
Silvana Bala ${ }^{1}$, Afrim Tabaku² \\ ¿University Hospital for Lung Diseases, Tirana, Albania \\ 2Public Health Institute, Tirana, Albania
}

\section{SUMMARY}

Metallurgical industry workers in developing countries are often exposed to high concentrations of dusts and fumes that affect pulmonary function. The aim of this cross-sectional study is to assess the prevalence and severity of chronic obstructive pulmonary disease (COPD), the prevalence of symptoms, as well as, the link between work-place air pollution and COPD.

A standardized questionnaire was used to collect data about smoking and socioeconomic status, past history of pulmonary diseases, current respiratory symptoms, education, and other variables. We have identified and assessed all risk factors and also have performed measurements of dynamic pulmonary function in 459 subjects - $90 \%$ of iron-steel and ferrochrome industry workers. The prevalence of COPD oscillated from $19.6 \%$ up to $25.7 \%$ while severity varied from mild to very severe.

Symptoms: prevalence varied from $12.0 \%$ to $46.3 \%$ while relative risk for developing COPD was 2.1-5.5 that of non-industry controls. Exposure markers' concentrations: for total suspended particles (TSP) oscillated from $0.375-25.5 \mathrm{mg} / \mathrm{m}^{3}$, particulate matter (PM10) from 0.25 to $10.5 \mathrm{mg} / \mathrm{m}^{3}$, and sulfur dioxide from $0.19-18.69 \mathrm{mg} / \mathrm{m}^{3}$. In majority of cases its average exceeded threshold limit values.

Our conclusion was that COPD prevalence and its symptoms are high in the population studied, and that there exists a well established occupational risk between work-place air pollution and COPD.

Key words: air pollution, chronic obstructive pulmonary disease, occupational exposure, risk factors, smoking behavior, pulmonary function testing, threshold limit values (TLV)

Address for correspondence: S. A. Bala, University Hospital for Lung Diseases, Tirana, Albania. E-mail: silvana.bala@ yahoo.co.uk

\section{INTRODUCTION}

Metallurgical industry workers are often exposed to harmful gases and dusts that affect pulmonary function and cause chronic obstructive pulmonary disease (COPD). Occupational dusts and chemicals can cause COPD when the exposure is sufficiently intense or prolonged, such of those experienced in heavy industry or in mining. These exposures can cause COPD independently of cigarette, while the risk is substantially higher in the presence of concurrent cigarette smoking (1-4).

COPD is the most frequent chronic disease in developing country workers. Aging and archaic technology and high concentrations of workplace air pollutants are the main but definitely not the only culprits. Exposure to particulate matter, irritants, organic dusts, and sensitizing agents cause an increase in airway hyperresponsiveness, especially in airways already damaged by other occupational exposures, cigarette smoking, and/or asthma $(1,5)$. Most of the evidence regarding the risk factors for development of COPD comes from cross-sectional epidemiological studies that identify association $(1,6,7,8)$.

The aim of this cross-sectional study was to assess the prevalence and severity of COPD, the prevalence of symptoms, as well as, to quantify any correlation between occupational area air pollution and COPD.

\section{MATERIALS AND METHODS}

We have used a standardized questionnaire, based on a modified version of an American Thoracic Society (ATS) questionnaire, to collect data on smoking habits, socioeconomic status, past history of pulmonary diseases, current respiratory symptoms (chronic cough, chronic phlegm, wheezing and whispering, breathlessness, dyspnea in efforts), education, job exposure matrix, and other parameters (9). We have performed measurement of pulmonary function in 459 subjects which represent $90 \%$ of staff working in Albanian iron-steel and ferrochrome industry, and have identified, assessed and analyzed for all risk factors. Office workers formed the reference/control group. Following variables were measured: forced vital capacity (FVC), forced expiratory volume in the first second after full inspiration $\left(\mathrm{FEV}_{1}\right), \mathrm{FEV}_{1} / \mathrm{FVC}$ ratio, peak expiratory flow rate (PEF), forced expiratory flow $\left(\mathrm{FEF}_{25-75}\right)$, and vital capacity (VC). Each subject produced at least three acceptable FVC curves based on ATS standards (10). The equipment used 
for pulmonary function measurements was calibrated using a 31 syringe, before each set of measurements (10).

According Global Initiative for Chronic Lung Disease (GOLD) criteria COPD is a preventable and treatable disease with some significant extra pulmonary effects that may contribute to the severity in individual patients. Its pulmonary component is characterized by airflow limitation that is not fully reversible. The airflow limitation is usually progressive and associated with an abnormal inflammatory response of the lung to noxious particles or gases. Classification of COPD severity, according these criteria were defined: mild: $\mathrm{FEV}_{1} / \mathrm{FVC}<70 \%$ but $\mathrm{FEV}_{1} \geq 80 \%$ predicted; moderate: $\mathrm{FEV}_{1} / \mathrm{FVC}<70 \%$ but $50 \% \leq \mathrm{FEV}_{1}<80 \%$ predicted; severe: $\mathrm{FEV}_{1} / \mathrm{FVC}<70 \%$ but $30 \leq \mathrm{FEV}_{1}<50 \%$ predicted, very severe: $\mathrm{FEV}_{1} / \mathrm{FVC}<70 \%, \mathrm{FEV}_{1} \leq 30 \%$ predicted or $\mathrm{FEV}_{1}<50 \%$ plus chronic respiratory failure and right heart failure (11).

We have compared the prevalence of COPD of exposed workers, with the prevalence of COPD of office workers (administrative staff) which was considered as control group.

Environmental sampling, during a typical work-day, was collected in workers breathing zone, in all technological processing units in these plants, and are analyzed for: (i) total suspended particles (TSP), (ii) particulate matter $\left(\mathrm{PM}_{10}\right)$, by gravimetric cascade impact method and, sulfur dioxide $\left(\mathrm{SO}_{2}\right)(12)$.

Statistical processing of the data was carried out using Statistical Package for Social Science (SPSS 15). Multiples regression is used to analyze the correlation between variables, whereas relative risk is calculated based on 2x2 contingency tables (Levine).

\section{RESULTS AND DISCUSSION}

Generally, the majority of workers in metallurgical industry are male. Due to the uneven gender distribution between the groups, women were excluded from the study. In order to avoid the "healthy worker effect", information was taken regarding their individual working histories. The age of workers, that were included in the study was 20-55+ years (Table 7). It resulted that $73.2 \%$ of iron steel production workers, $77.6 \%$ of iron steel processing workers, and $78.2 \%$ of ferrochrome workers fall in the range 31-50 years old.

The exposure time of workers in enterprises of metallurgical industry under study varied from 3-35 years, with an average exposure time of 25 years. Exposed $\leq 10$ years were $17.9 \%, 11-20$ years $23.1 \%$, $21-30$ years $55.5 \%$, and above 30 years $3.5 \%$ of iron steel production workers. In iron steel processing 4.5\%, 17.1\%, $64.2 \%$ and $14.2 \%$ workers respectively, whereas in ferrochrome production $14.5 \%, 49.6 \%, 25.6 \%$ and $10.3 \%$ workers respectively were exposed.

The prevalence of COPD in exposed workers is presented in Table 1, whereas in Tables 2 and 3 are presented the prevalence of COPD after stratification by exposure, as well as the prevalence of COPD in control groups. The overall prevalence of COPD for iron steel production and ferrochrome production as entire enterprises are also presented in these tables.

The data obtained after exposure stratification has shown that smelter and furnace workers have the highest prevalence of COPD: $42.4 \%$ and $35.4 \%$ respectively, followed by casters and other professional groups. Review of the literature shows similar findings by other researchers (23-25).
The severity of COPD (Table 4) showed the following variance amongst the three groups: $0.7-1.6 \%$ in mild, $14.3-17.5 \%$ in moderate, $2.1-6.0 \%$ severe and $0.0-1.6 \%$ for the few very severe COPD cases.

The highest prevalence of chronic cough was in iron steel production workers $(40.1 \%)$ while chronic phlegm was highest in iron steel processing workers (46.3\%). Wheezing ranged between 12.0-20.2\%, breathlessness varied from $12.0-13.9 \%$, whereas dyspnea on exertion ranged from 22.5-37.0\% between the groups studied (Table 5 and 6, Fig. 1).

Data on smoking habits are presented in Table 8. Packs/year cigarette consumption varied from 5 to 60 packs/year. About $50 \%$ of smoking persons consumed 6-20 packs/year for each type of enterprise.

The control groups had a history of employment in metallurgical industries which lasted from $10-30$ years. In this range $76.4 \%$ of iron steel production office workers, $100 \%$ of iron steel processing office workers and $47 \%$ of ferrochrome office workers were included.

Prevalence of smoking habits in iron steel production control group was $23.5 \%$, in iron steel processing $22.2 \%$ and in ferrochrome production $43.7 \%$. Cigarette consumption oscillated from 5 to 60 packs/year.

Table 1. Prevalence of COPD in exposed workers

\begin{tabular}{|l|c|c|}
\hline Enterprise & $\begin{array}{c}\text { Number of } \\
\text { workers }\end{array}$ & $\begin{array}{c}\text { Prevalence of } \\
\text { COPD \% }\end{array}$ \\
\hline Iron-steel production & 166 & 27.10 \\
\hline Iron-steel processing & 134 & 20.89 \\
\hline Ferrochrome production & 117 & 21.36 \\
\hline
\end{tabular}

Tables $2+3$ present data on prevalence of COPD after stratification based on levels of exposure to dusts and other air pollutants.

Table 2. Prevalence of COPD in iron steel workers stratified by processing type

\begin{tabular}{|l|c|c|c|}
\hline \multirow{2}{*}{ Processing type } & \multirow{2}{*}{$\begin{array}{c}\text { Number } \\
\text { of workers }\end{array}$} & \multicolumn{2}{|c|}{ COPD } \\
\cline { 3 - 4 } & & Cases & Prevalence \% \\
\hline Smelters & 59 & 25 & 42.37 \\
\hline Furnace workers & 24 & 6 & 25.00 \\
\hline Casters & 22 & 4 & 18.18 \\
\hline Workers at distance & 61 & 10 & 16.39 \\
\hline Administrative staff & 17 & 2 & 11.76 \\
\hline Enterprise in general & 183 & 47 & 25.68 \\
\hline
\end{tabular}

Table 3. Prevalence of COPD in ferrochrome workers stratified by processing type

\begin{tabular}{|l|c|c|c|}
\hline \multirow{2}{*}{ Processing type } & \multirow{2}{*}{$\begin{array}{c}\text { Number } \\
\text { of workers }\end{array}$} & \multicolumn{2}{|c|}{ COPD } \\
\cline { 3 - 4 } & & Cases & Prevalence \% \\
\hline S melters & 48 & 17 & 35.41 \\
\hline Casters & 28 & 5 & 17.86 \\
\hline Row material workers & 24 & 2 & 8.33 \\
\hline Mechanics & 17 & 1 & 5.88 \\
\hline Administrative staff & 16 & 1 & 6.25 \\
\hline Enterprise in general & 133 & 26 & 19.54 \\
\hline
\end{tabular}


Table 4. COPD severity

\begin{tabular}{|l|c|c|c|}
\hline \multirow{2}{*}{ COPD severity } & \multicolumn{3}{|c|}{ Enterprises } \\
\cline { 2 - 4 } & $\begin{array}{c}\text { Iron-steel } \\
\text { production }\end{array}$ & $\begin{array}{c}\text { Iron-steel } \\
\text { processing }\end{array}$ & $\begin{array}{c}\text { Ferrochrome } \\
\text { production }\end{array}$ \\
\hline At risk & $16(8.7 \%)$ & $11(7.7 \%)$ & $7(5.3 \%)$ \\
\hline Mild COPD & $3(1.6 \%)$ & $1(0.7 \%)$ & $1(0.8 \%)$ \\
\hline Moderate COPD & $30(16.4 \%)$ & $25(17.5 \%)$ & $19(14.3 \%)$ \\
\hline Severe COPD & $11(6.0 \%)$ & $3(2.1 \%)$ & $4(3.0 \%)$ \\
\hline Very severe COPD & $3(1.6 \%)$ & $0(0.0 \%)$ & $2(1.5 \%)$ \\
\hline
\end{tabular}

Table 5. Prevalence of symptoms

\begin{tabular}{|l|c|c|c|}
\hline \multirow{2}{*}{ Symptoms } & \multicolumn{3}{|c|}{ Prevalence in \% } \\
\cline { 2 - 4 } & $\begin{array}{c}\text { Iron steel } \\
\text { production }\end{array}$ & $\begin{array}{c}\text { Iron steel } \\
\text { processing }\end{array}$ & $\begin{array}{c}\text { Ferrochrome } \\
\text { production }\end{array}$ \\
\hline Chronic cough & 40.09 & 39.50 & 25.00 \\
\hline Chronic phlegm & 33.87 & 46.30 & 28.08 \\
\hline Wheezing and whispering & 20.21 & 18.80 & 12.02 \\
\hline Breathlessness & 13.15 & 13.90 & 12.02 \\
\hline Dispnea in efforts & 32.79 & 37.00 & 22.53 \\
\hline
\end{tabular}

Table 6. Odds ratio of symptoms for workers of iron steel production, iron steel processing and ferrochrome plant

\begin{tabular}{|c|c|c|c|}
\hline \multirow{2}{*}{ Symptoms } & Iron steel production & Iron steel processing & Ferrochrome production \\
\hline & OR (CI 95\%) & OR (CI 95\%) & OR (CI 95\%) \\
\hline Chronic cough & 3.3 (CI 95\% $1.65-6.69)$ & 2.6 (CI 95\% $1.43-8.12)$ & 2.1 (CI 95\% $1.13-3.87)$ \\
\hline Chronic phlegm & 5.9 (CI 95\% $2.76-12.82)$ & $5.4(\mathrm{Cl} 95 \% 1.74-10.25)$ & 4.7 (CI 95\% $2.08-6.40)$ \\
\hline Wheezing and whistling & $2.0(\mathrm{Cl} 95 \% 0.97-4.40)$ & $1.6(\mathrm{Cl} 95 \% 1.00-4.50)$ & $1.3(\mathrm{Cl} 95 \% 0.99-3.89)$ \\
\hline Breathlessness & 1.7 (CI 95\% $0.72-7.99)$ & 1.11 (CI 95\% $0.82-6.38)$ & 1.1 (CI 95\% $0.85-5.04)$ \\
\hline Dyspnea in efforts & $2.6(\mathrm{Cl} 95 \% 0.69-11.99)$ & $1.96(\mathrm{Cl} 95 \% 0.74-12.58)$ & $2.0(\mathrm{Cl} 95 \% 0.90-6.85)$ \\
\hline
\end{tabular}

OR $=$ Odds Ratio

$\mathrm{Cl} 95 \%=95 \%$ Conf dence Interval

Table 7. Distribution of prevalence of COPD by age

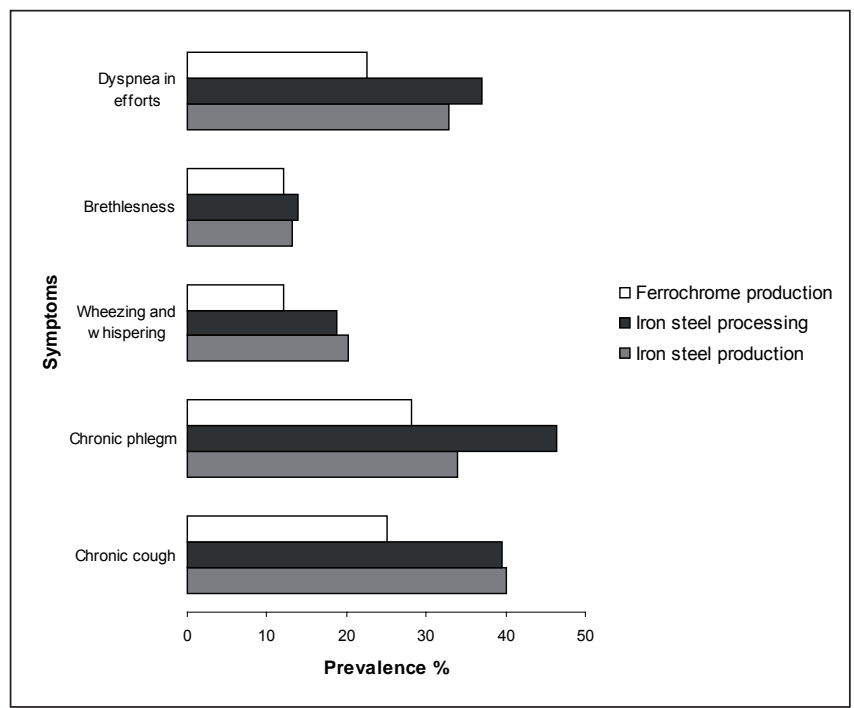

\begin{tabular}{|c|c|c|c|}
\hline \multirow{2}{*}{$\begin{array}{c}\text { Age groups } \\
\text { (years) }\end{array}$} & \multicolumn{3}{|c|}{ COPD prevalence } \\
\cline { 2 - 4 } & $\begin{array}{c}\text { Iron-steel } \\
\text { production }\end{array}$ & $\begin{array}{c}\text { Iron-steel } \\
\text { processing }\end{array}$ & $\begin{array}{c}\text { Ferrochrome } \\
\text { production }\end{array}$ \\
\hline $20-30$ & $16.7 \%$ & $16.7 \%$ & $12.5 \%$ \\
\hline $31-40$ & $23.9 \%$ & $20.7 \%$ & $17.8 \%$ \\
\hline $41-50$ & $26.3 \%$ & $19.8 \%$ & $18.6 \%$ \\
\hline$>50$ & $30.0 \%$ & $22.2 \%$ & $28.6 \%$ \\
\hline
\end{tabular}

Table 8. Smoking status of workers by type of enterprise

\begin{tabular}{|l|c|c|c|}
\hline \multirow{2}{*}{ Enterprises } & \multicolumn{3}{|c|}{ Smoking habit } \\
\cline { 2 - 4 } & Non smokers & Ex smokers & $\begin{array}{c}\text { Current } \\
\text { smokers }\end{array}$ \\
\hline Iron-steel production & $41.5 \%$ & $12.6 \%$ & $45.9 \%$ \\
\hline Iron-steel processing & $47.6 \%$ & $11.2 \%$ & $41.2 \%$ \\
\hline Ferrochrome production & $51.9 \%$ & $10.5 \%$ & $38.6 \%$ \\
\hline
\end{tabular}

Fig. 1. Prevalence of symptoms in exposed workers.

Table 9 compares COPD prevalence in the three groups above and found it to be highest in current smokers.

Table 9. Prevalence of COPD based on smoking status by type of enterprise

\begin{tabular}{|c|c|c|c|c|c|c|c|c|c|}
\hline \multirow{3}{*}{ Enterprise } & \multicolumn{9}{|c|}{ COPD prevalence } \\
\hline & \multicolumn{3}{|c|}{ Non smokers } & \multicolumn{3}{|c|}{ Ex smokers } & \multicolumn{3}{|c|}{ Current smokers } \\
\hline & Nr. & Cases & $\%$ & Nr. & Cases & $\%$ & Nr. & Cases & $\%$ \\
\hline Iron-steel production & 76 & 14 & 18.4 & 23 & 5 & 21.7 & 84 & 25 & 29.8 \\
\hline Iron-steel processing & 68 & 8 & 11.8 & 16 & 4 & 25.0 & 59 & 18 & 30.5 \\
\hline Ferrochrome production & 59 & 10 & 17.0 & 14 & 2 & 14.3 & 60 & 15 & 25.0 \\
\hline
\end{tabular}


Table 10. Air pollution of occupational area

\begin{tabular}{|c|c|c|c|}
\hline \multirow[t]{2}{*}{ Enterprises } & \multicolumn{3}{|c|}{$\begin{array}{l}\text { Range of concentrations of pollutants } \\
\left(\mathrm{mg} / \mathrm{m}^{3}\right) \text { in air of occupational area }\end{array}$} \\
\hline & TSP & $\mathrm{PM}_{10}$ & $\mathrm{SO}_{2}$ \\
\hline Iron-steel production & $2.4-25.5$ & $1.05-10.5$ & $2.67-18.69$ \\
\hline Iron-steel processing & $0.250-3.5$ & $0.01-0.07$ & $2.67-8.01$ \\
\hline Ferrochrome production & $0.375-14.52$ & $0.25-0.61$ & $0.19-2.22$ \\
\hline
\end{tabular}

Environmental sampling was conducted in all units of the three enterprises, and the results of analysis are presented in Table 10.

COPD is a leading cause of mortality and morbidity in both developed and developing countries and its natural history is mainly characterized by progressive irreversible decline in

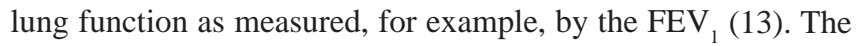
multifactorial etiology and manifestation of COPD has led to the development of the "Dutch hypothesis" regarding its natural history and which holds that asthma, chronic bronchitis and emphysema are different expressions of one disease entity in which the tendency to develop allergy and airway hyperresponsiveness are modulated by such factors as age and gender as well as other extrinsic factors (14).

Occupational-related causes of COPD and chronic bronchitis and emphysema (CBE) have been addressed by a wide-range of industry based studies, including cohort and case-control designs, population or community-based studies (15-18). Long-term exposure to fumes, chemical substances and dusts in the workplace have been mentioned as risk factors for the development of COPD.

Minute particles are formed when molten metals coagulate in air due to temperature gradients outside the furnace. Without proper personal protective equipment (not readily available in developing countries) these particles are easily inhaled, reach the alveoli, and have permanent damaging effects on respiratory function.

Occupational exposure has been related to several respiratory diseases, mainly with bronchial asthma and COPD (13, 19, 20). Several epidemiological studies have found an association between occupational exposure to dust, fumes and gases, and chronic bronchitis and airflow obstruction (1, 6-8, 20-22). The role of occupational exposure in the development of chronic airflow obstruction is still controversial. One of the main reasons for this is the difficulty in assessing the independent effect of occupational exposure and smoking (14-16). Both risk factors are determined by amount as well as duration of exposure. Even after adjusting associations between occupational exposure and COPD for smoking status, a residual confounding effect remains. In addition, an interaction between occupational exposures and smoking has been described (17). For all these reasons it has been argued that a separate analysis of smokers and non-smokers is preferable $(8,17)$.

Past occupational exposures significantly increased the likelihood of COPD independently of the confounding effects of smoking. Given that one in five cases of COPD may be attributable to occupational exposure, clinicians and health policy-makers should address this potential avenue of COPD causality and institute occupational ambient air-safety safeguards.
Table 11. The relationship between occupational area air pollution and the possibility for developing COPD in exposed workers

\begin{tabular}{|l|c|c|c|}
\hline Enterprise & $\begin{array}{c}\text { Number of } \\
\text { workers }\end{array}$ & $\begin{array}{c}\text { Crude relative } \\
\text { risk }\end{array}$ & $\begin{array}{c}\text { Adjusted } \\
\text { relative risk* }\end{array}$ \\
\hline Iron-steel & 166 & $5.51(\mathrm{Cl} 95 \%$ & $5.11(\mathrm{Cl} 95 \%$ \\
production & & $3.98-6.73)$ & $3.30-6.50)$ \\
\hline Iron-steel & 134 & $2.09(\mathrm{Cl} 95 \%$ & $1.89(\mathrm{CI} 95 \%$ \\
processing & & $1.71-2.95)$ & $1.60-2.90)$ \\
\hline Ferrochrome & 117 & $4.08(\mathrm{Cl} 95 \%$ & $3.81(\mathrm{Cl} 95 \%$ \\
production & & $2.11-5.88)$ & $1.95-5.85)$ \\
\hline
\end{tabular}

*Age-smoking adjusted

On the other hand, when evaluating the effect of occupational exposure on lung function it is important to take into account the duration of lifetime exposure. Cumulative exposure to dust and increasing working years in specific jobs have been associated with a steeper decline in forced expiratory volume $1(18,23)$. Although workforce-based studies allow an accurate measure of occupational exposures, selection bias is more likely to occur due to the healthy worker effect (24).

While other risk factors are consistently identified, research mainly relates to diagnostic and treatment strategies with little regard to identifying workers at risk of this condition by virtue of harmful workplace exposures. However, various recent studies have assessed the effect of workplace exposures on COPD, and reveal that a proportion of the total "COPD burden" is caused by airborne occupational exposures, in addition to cigarette smoking $(1,3,5,6,17)$.

The present findings support an association between COPD and occupational inhalant exposures (Table 11). Increases of $100 \%$ in the risk of COPD due to workplace factors were observed, even after taking into account the impact of cigarette smoking. The risks estimated in the present study are in the range of those reported by other investigators $(15,25)$. Literature review suggests that $15 \%$ of all COPD could be attributed to occupational exposures. Furthermore, few were designed a priori to focus on occupation as a risk factor for COPD but rather used a population based approach of older adults and who are immediately at greatest risk of disease.

The prevalence rates of chronic respiratory symptoms were higher in subjects reporting high levels of occupational exposures. These associations were more pronounced in never-smokers, while wheezing was also associated with occupational exposures in ex-smokers.

Table 7 shows that the over 50 age group is the most affected by COPD, but the prevalence in the younger age group (20-30 years) is also high. It is entirely possible that a disease continuum exists which can best be tested via a prospective study. Barring funding restrictions, we aim to prospectively evaluate Pulmonary Parameters and COPD Prevalence Progression of both Case and Control groups prospectively and report back to the Scientific Community.

The role of cigarette smoking appears to be complex. In the present analysis as well as from other studies $(15,22,25)$ evidence was found for an interaction between smoking and occupational exposures, such that current or former smokers reporting job 
exposure were at significantly higher risk for COPD. This is biologically plausible, since irritant gas and particulate exposures could interact in either additive or multiplicative ways in the initiation and progression of chronic bronchitis, emphysema or airflow obstruction.

Cigarette smoking remains the predominant cause of COPD and is appropriately at the forefront of public health efforts for prevention of lung diseases. Nonetheless, the present findings support the observations of other researchers that COPD relates to occupation independent of smoking status. Clinicians and healthcare policy-makers need to take workplace conditions into account, perhaps all the more so among smokers, when developing prevention strategies. Workplace smoking should be banned altogether while smoking-cessation resources and employee counseling should be freely available.

The combination of exposure to airborne dust and smoking often resulted in pulmonary function abnormalities. Analysis of respiratory abnormalities of workers of three cast-iron foundries concluded that dust was not the only factor; smoking also contributed to respiratory abnormalities (21).

Another explanation of our findings could be that the effect of occupational exposure is proportionally smaller to that of smoking, and thus easier to detect among never-smokers.

In this study we have obtained statistical differences between exposed and control groups regarding the main pulmonary function, like FVC $(\mathrm{P}=0.002)$ in iron steel production workers $(\mathrm{P} \leq 0.001)$, in iron steel processing workers, and $(\mathrm{P}=0.008)$ in ferrochrome production workers, whereas significance for $\mathrm{FEV}_{1}$ were $\mathrm{P} \leq 0.001, \mathrm{P}=0.003$ and $\mathrm{P}=0.005$, respectively.

Environmental sampling was conducted in all units of the three enterprises (Table 8). Area sampling was performed to measure total airborne dust concentrations, of which the smelting and moulding areas are tested highest (20.2-25.5 mg/m $\mathrm{m}^{3}$ ). Total airborne dust concentrations in the administrative areas are were comparably low $\left(<0.3 \mathrm{mg} / \mathrm{m}^{3}\right)$, whereas concentrations of $\mathrm{PM}_{10}$ were very low $\left(<5 \mu \mathrm{g} / \mathrm{m}^{3}\right)$ Respirable dust concentration varied from $3.90-8.10 \mathrm{mg} / \mathrm{m}^{3}$ for the smelting unit in iron steel production, $0.01-0.07 \mathrm{mg} / \mathrm{m}^{3}$ in iron steel processing, and $0.26-0.30 \mathrm{mg} / \mathrm{m}^{3}$ in ferrochrome production (Table 10). The averages of these data on occupational air pollution exceed threshold limits values (26). As it is shown in Tables 2 and 3, the prevalence of COPD is higher in units, where the concentrations of pollutants are higher than other units of enterprise.

Results obtained regarding air pollution in iron steel processing, as presented in Table 10, are within threshold limit values, but the higher prevalence of COPD in these group of workers may be explained by the fact that they have previously worked in iron steel production, and after their lungs have been affected by pollutants, are transferred in iron processing plant where the air pollution is less severe then in their previous working place.

Table 8 and 9 of this study show a very high prevalence of COPD in non-smokers (11.8-18.4\%) and it is thus the authors' conclusion that COPD in non-smokers is due to occupational exposure independent of cigarette smoking while COPD prevalence increases in the presence of concurrent cigarette smoking.

\section{CONCLUSIONS}

This data shows a strong correlation between occupational area air pollution and the possibility for developing COPD, especially when data for relative risk were adjusted for smoking and age. Overall prevalence of COPD from this survey was highest among iron-steel production workers, and lowest among ferrochrome production workers.

\section{Acknowledgements}

The authors would like to thank all colleagues of Public Health Institute who contributed to the measurements of air pollution of occupational area.

\section{REFERENCES}

1. Trupin L, Earnest G, San Pedro M, Balmes JR, Eisner MD, Yelin E, et al. The occupational burden of chronic obstructive pulmonary disease. Eur Respir J. 2003 Sep;22(3):462-9.

2. Meijer E, Grobbee DE, Heederik DJ. Health surveillance for occupational chronic obstructive pulmonary disease. J Occup Environ Med. 2001 May;43(5):444-50.

3. Sobaszek A, Boulenguez C, Frimat P, Robin H, Haguenoer JM, Edme JL. Acute respiratory effects of exposure to stainless steel and mild steel welding fumes. J Occup Environ Med. 2000 Sep;42(9):923-31.

4. Banks DE, Shah AA, Lopez M, Wang ML. Chest illnesses and the decline of FEV1 in steelworkers. J Occup Environ Med. 1999 Dec;41(12):108590.

5. Meldrum M, Rawbone R, Curran AD, Fishwick D. The role of occupation in the development of chronic obstructive pulmonary disease (COPD). Occup Environ Med. 2005 Apr;62(4):212-4.

6. Fishwick D, Naylor S. COPD and the workplace. Is it really possible to detect early cases? Occup Med (Lond). 2007 Mar;57(2):82-4.

7. Mastrangelo G, Tartari M, Fedeli U, Fadda E, Saia B. Ascertaining the risk of chronic obstructive pulmonary disease in relation to occupation using a case-control design. Occup Med (Lond). 2003 May;53(3):16572.

8. Halbert RJ, Natoli JL, Gano A, Badamgarav E, Buist AS, Mannino DM. Global burden of COPD: systematic review and meta-analysis. Eur Respir J. 2006 Sep;28(3):523-32.

9. Chang CC. Study on the pneumoconiosis of foundry workers in central Taiwan [masters thesis]. Taichung: Institute of Environmental Health, China Medical College; 1995.

10. Standardization of spirometry, 1994 update. American Thoracic Society. Am J Respir Crit Care Med. 1995 Sep;152(3):1107-36.

11. Global Initiative for Chronic Obstructive Lung Disease. Global strategy for the diagnosis, management, and prevention of chronic obstructive pulmonary disease (GOLD). Medical Communication Resources; 2006.

12. Lodge JP, editor. Methods of air sampling and analysis. 3rd ed. Boca Raton: Lewis Publishers; 1988.

13. Antó JM, Vermeire P, Vestbo J, Sunyer J. Epidemiology of chronic obstructive pulmonary disease. Eur Respir J. 2001 May;17(5):982-94.

14. Becklake MR. Airways disease and occupational exposure to nonfibrogenic dust. Appl Occup Environ Hyg. 1998;13:586-92.

15. Hendrick DJ. Occupational and chronic obstructive pulmonary disease (COPD). Thorax. 1996 Sep;51(9):947-55.

16. Garshick E, Schenker MB, Dosman JA. Occupationally induced airways obstruction. Med Clin North Am. 1996 Jul;80(4):851-78.

17. Viegi G, Di Pede C. Chronic obstructive lung diseases and occupational exposure. Curr Opin Allergy Clin Immunol. 2002 Apr;2(2):115-21.

18. Balmes J, Becklake M, Blanc P, Henneberger P, Kreiss K, Mapp C, et al; Environmental and Occupational Health Assembly, American Thoracic Society. American Thoracic Society Statement: occupational contribution to the burden of airway disease. Am J Respir Crit Care Med. 2003 Mar 1;167(5):787-97.

19. Ulvestad B, Bakke B, Eduard W, Kongerud J, Lund MB. Cumulative exposure to dust causes accelerated decline in lung function in tunnel workers. Occup Environ Med. 2001 Oct;58(10):663-9. 
20. Post W, Heederik D, Houba R. Decline in lung function related to exposure and selection processes among workers in the grain processing and animal feed industry. Occup Environ Med. 1998 May;55(5):349-55.

21. Caudarella R, Gennari P, Tabaroni G, Cascella D, Raffi GB. Respiratory disease in foundry workers. An epidemiological survey in three foundries. Lav Um. 1976 Sep;28(5):129-41. (In Italian.)

22. Burge PS. Occupation and chronic obstructive pulmonary disease (COPD). Eur Respir J. 1994 Jun;7(6):1032-4.

23. Oxman AD, Muir DC, Shannon HS, Stock SR, Hnizdo E, Lange HJ. Occupational dust exposure and chronic obstructive pulmonary disease. A systematic overview of the evidence. Am Rev Respir Dis. 1993 Jul;148(1):38-48.
24. Zock JP, Sunyer J, Kogevinas M, Kromhout H, Burney P, Antó JM. Occupation, chronic bronchitis, and lung function in young adults. An international study. Am J Respir Crit Care Med. 2001 Jun;163(7):1572-

25. Kolarzyk E, Stepniewski M, Zapolska I. Occurrence of pulmonary diseases in steel mill workers. Int J Occup Med Environ Health. 2000;13(2):103-12.

26. American Conference of Governmental Industrial Hygienists. Threshold limit values 2000. Cincinnati: ACGIH; 2000.

Received February 16, 2009 Accepted in revised form February 5, 2010 